\title{
Participación política, compromiso y carrera militante. Una propuesta para el estudio de la militancia en el contexto del activismo global*
}

\author{
ADRIÁN PABLO BERARDI SPAIRANI**
}

Artículo recibido: 11 de marzo de 2019

Artículo aceptado: 15 de julio de 2019

Doi: https://www.doi.org/10.12804/revistas.urosario.edu.co/desafios/a.7751

Para citar este artículo: Berardi Spairani, A. P. (2020). Participación política, compromiso y carrera militante. Una propuesta para el estudio de la militancia en el contexto del activismo global. Desafios, 32(2), 1-37. http://www.doi.org/10.12804/revistas.urosario.edu. co/desafios/a.7751

\section{Resumen}

Este articulo se propone analizar la participación y el compromiso politico por medio del estudio de la carrera militante. El objetivo es dar cuenta de cómo se construye una trayectoria militante exitosa que persiste más allá del tiempo, y que se diferencia de un tipo de militancia parcial o puntual. De esta manera, el presente trabajo estudia

\footnotetext{
* El presente artículo forma parte del trabajo realizado en el marco de mi tesis doctoral El mundo militante en la democracia argentina contemporánea. Un estudio de trayectorias militantes en la provincia de Jujuy. Dicha investigación fue realizada con financiamiento parcial con una Beca de Finalización Doctoral del Consejo de Investigaciones Científicas y Tecnológicas (CONICET) del Ministerio de Ciencia, Tecnología e Innovación Productiva entre los años 2016 a 2018.

** Instituto de Altos Estudios Sociales, Universidad Nacional San Martín (Buenos Aires, Argentina); Instituto de Ciencias, Universidad Nacional de General Sarmiento (Buenos Aires, Argentina). Correo electrónico: adrianberardi@gmail.com. orcID: http://orcid. org/0000-0003-4269-7400
} 


\title{
2 I Adrián Pablo Berardi Spairani
}

las formas de militancia contemporánea, con el objetivo de responder si es posible pensar la participación política como una militancia sostenida en el tiempo y cuáles son los recursos que poseen las ciencias sociales para diferenciar los distintos tipos de militancias dentro de un periodo marcado por la globalización. Para dar respuesta a los interrogantes planteados se desarrolló un estudio longitudinal de trayectorias militantes al examinar los aspectos objetivos y subjetivos, a partir del relato de los propios militantes, bajo la perspectiva de carrera desarrollada por Howard Becker. En la metodología se describe la utilización de una perspectiva cualitativa a partir del uso de la técnica del relato de vida.

Palabras claves: participación politica; carrera militante; compromiso politico; activismo; militancia.

\section{Political participation, commitment and militant career. A proposal for the study of partisanship in the context of global activism}

\begin{abstract}
In this article, we proposed to analyze participation and political commitment through the study of activist biographies. The objective is to give an account of how a successful activist trajectory of more than passing temporal relevance is constructed. In this way, the article studies the forms of contemporary activism, with the aim of answering if it is possible to think of political participation as sustained activism; and what are the resources that the social sciences possess to differentiate the different types of activism in an age of globalization. To answer the questions raised, a longitudinal study of activist trajectories was carried out, examining objective and subjective aspects, based on the narration of the activists themselves, recovering the perspective developed by Howard Becker. Methodologically, a qualitative perspective was used, based on the life story technique.
\end{abstract}

Keywords: Political participation; activist career; political commitment; activist; partisanship. 


\title{
Participação política, compromisso e carreira militante. Uma proposta para o estudo da militância no contexto do ativismo global
}

\begin{abstract}
Resumo
Neste artigo se propõe analisar a participação e compromisso politico através do estudo da carreira militante. O objetivo é dar conta de como se constrói uma trajetória militante bem-sucedida que persiste para além do tempo, que se diferencia de um tipo de militância parcial ou pontual. Desta maneira, o presente trabalho estuda as formas militância contemporânea, com o objetivo de responder se épossivel pensar a participação política como uma militância sustentada no tempo e quais são os recursos que possuem as ciências sociais para diferenciar os diferentes tipos de militâncias dentro de um período marcado pela globalização. Para dar resposta às questões apresentadas se levou a cabo um estudo longitudinal de trajetórias militantes examinando os aspetos objetivos e subjetivos, a partir do relato dos próprios militantes, recuperando a perspectiva de carreira desenvolvida por Howard Becker. Metodologicamente se utilizou uma perspectiva qualitativa a partir do uso da técnica do relato de vida.
\end{abstract}

Palavras-chave: participação política; carreira militante; compromisso político; ativismo; militância

\section{Introducción}

La participación política se constituye como una actividad o acción no profesional, voluntaria, que se dirige al sistema político en un sentido amplio (van Deth, 2014), al involucrar acciones orientadas al Estado, ya sea nacional o local, o - incluso- a corporaciones multinacionales en lo que Deutsch (2009) llama actividad desafiante de élite. Es decir, esta actividad implica múltiples objetivos e incorpora diferentes actos y espacios de participación, ya sea en movimientos sociales, acciones de protesta, participación partidaria o consumismo político (Dietlind, Hooghe \& Micheletti, 2005).

Inicialmente, la participación política se discutía desde un punto de vista institucional, que valorizaba la participación cívica dentro del 
sistema democrático (Milbrath, 1965, 1981) a través del voto. Esta perspectiva hizo hincapié en el desarrollo de las habilidades cívicas ${ }^{1}$ (Nie, Bingham Powell \& Prewitt,1969; Verba \& Nie, 1972) como la principal forma de involucramiento, pero condicionada por el acceso a ciertos niveles de educación (Verba \& Nie, 1972), la condición de clase o el clivaje social. De esta manera, el desarrollo de estas habilidades estaba enmarcado dentro del entorno social y permitía generar vínculos y relaciones que, por medio de los intercambios (discusiones, acceso a cierta información, etc.), incentivaban la participación (Huckfeldt, 1979; Leighley, 1990).

La otra variable de participación política se relacionaba con la pertenencia a las asociaciones voluntarias o "asociaciones no políticas" que permitían acceder a conocimientos y actividades comunales que tendían a impulsar la participación cívica, ${ }^{3}$ en tanto en ellas se produce un intercambio de ideas que facilitan el acceso a información política y promocionan un conjunto de habilidades, como los mecanismos en la toma de decisiones o la construcción de liderazgos que son aplicables en la práctica política (Nie, et al., 1969; Verba \& Nie, 1972; La Due Lake \& Huckfeldt, 1998; Ayala, 2000). ${ }^{4}$

Por otro lado, desde la perspectiva del estudio de los movimientos sociales se dio cuenta de nuevas formas de participación producto de los cambios generados en el periodo posindustrial que modificaron las prácticas políticas y forjaron un proceso de desafiliación, dando lugar a un tipo de actividades políticas, vinculadas a demandas específicas

\footnotetext{
1 En un principio, los trabajos que vinculan las habilidades cívicas a la participación política lo hacen analizando la práctica electoral y el involucramiento en ella por parte de los ciudadanos.

2 Ayala (2000) define asociaciones no políticas a aquellas estructuras vinculadas a la arena civil, como la iglesia, los espacios laborales o las asociaciones de beneficencia.

3 El trabajo de Vommaro y Morresi (2015) da cuenta de la forma en que activistas de organizaciones de este tipo comenzaron a vincularse a la militancia política o la participación político-partidaria a partir de la conformación del partido Pro en la Argentina.

4 En este punto es importante hacer énfasis en que en los trabajos de Nie et al. (1969) y de Verba y Nie (1972) el acceso a las habilidades cívicas, sea por educación o pertenencia a asociaciones voluntarias, está condicionado a la situación socioeconómica de las personas.
} 
y más allá de las estructuras tradicionales (Kitschelt, 2004; Fillieule \& Tartakosky, 2015).

La discusión en torno a las nuevas formas de participación política comenzó a tomar fuerza a finales de los años sesenta, ${ }^{5}$ cuando los límites que separaban la militancia integral de un activismo puntual, es decir, el involucramiento a organizaciones burocráticas y jerarquizantes (como los partidos políticos y los sindicatos) y los espacios de participación caracterizados por un repertorio de acción más disruptivo y beligerante por fuera de espacios más tradicionales (Modonesi, 2016), comenzaron a desdibujarse. Lo anterior, producto de los cambios en las estructuras productivas y en el proceso de globalización económica, modificó también las lógicas de solidaridad entre los sectores que componían la clase trabajadora (Della Porta \& Diani, 2011; Rosanvallon, 2007), y pusieron en discusión los viejos paradigmas de la actividad militante (Sawicki \& Siméant, 2009). Estos cambios generaron un proceso de desafiliación y fragmentación del movimiento obrero (Ion, 1997), lo que produjo una desarticulación de la militancia integral en los partidos políticos y en los sindicatos, y dio forma a los nuevos movimientos sociales (Della Porta \& Diani, 2011).

Estas transformaciones generaron un tipo de militancia que desarrolló una práctica militante más trasversal e introdujo una agenda política sujeta a nuevos tipos de demandas o problemáticas específicas como humanismo, feminismo, ecologismo, entre otras (Sawicki \& Siméant,

\footnotetext{
5 En este trabajo se tomó como referencia el proceso de conformación de una militancia global teniendo en cuenta la configuración de los nuevos movimientos sociales que emergen desde las décadas de 1960 y 1970, dentro de lo que algunos autores consideraron el Paradigma Utópico Revolucionario (Pastore, 2010), y que se consolidaron entre los años 1990 y 2000. Estos últimos estaban principalmente vinculados a las trasformaciones de la estructura social, producto de los cambios en el mercado de trabajo y el sistema productivo.

No obstante, es posible considerar que antes de los periodos mencionados se configuró un tipo de militancia internacionalista, como por ejemplo la "Comintern" o "Internacional Comunista” (Studer, 2015). Algo similar sucedió con la generación de reformistas en América Latina a fines de la década del 1910 (Portantiero, 1978; Bergel \& Martínez Mazzola, 2012); como así también otros espacios u organizaciones de carácter internacional que surgieron a principios de siglo Xx como la Liga Antiimperialista de las Américas (Bergel, 2011).
} 


\section{I Adrián Pablo Berardi Spairani}

2009). Esta forma de activismo permitió el surgimiento de lo que Pudal (2011) denominó "militantes distanciados" (p.19).

Por otra parte, estas formas emergentes de participación quedaron sujetas a las nuevas dinámicas geopolíticas y emergieron de movimientos sociales globales, integrados por organizaciones de distintos países que se acoplaron a los movimientos locales (Della Porta \& Tarrow, 2005). Estas consideraban los conflictos domésticos como resultados de las transformaciones globales y exigían ante las autoridades internacionales la resolución de los conflictos regionales (Della Porta \& Tarrow, 2005).

Estas acciones de protesta global traspasaron las fronteras de los países y crearon un tipo de militancia novedoso. Es posible distinguir estas nuevas formas de participación política en el movimiento Occupy Wall Street en los Estados Unidos (Calhoun, 2013; Carty, 2015) y en el movimiento de los indignados en España (Romanos, 2017), producto de la crisis financiera mundial de 2008. También en los movimientos de protesta y ocupación de la vía pública en Europa, conocidos como los movimientos antiausteridad (Della Porta, 2015; Gerbaudo, 2016; Della Porta et al., 2017), así como en los movimientos anti globalización (Fillieule \& Accornero, 2016). Por último, en la expansión de los movimientos de protesta contra los regímenes autoritarios, así como las manifestaciones en Túnez y Egipto, que consolidaron la Primavera Árabe (Abdelali, 2013; Sakbani, 2011).

A estos acontecimientos, se les suman las movilizaciones de mujeres en demanda por sus derechos, como lo que sucedió en Argentina en las movilizaciones \#NiUnaMenos (Laudano, 2017) y aquellas vinculadas a la discusión por el proyecto de la Ley de Interrupción Voluntaria del Embarazo, "la marea verde" (Elizalde \& Mateo, 2018). Al mismo tiempo, esta nueva militancia incorporó como herramientas de participación y organización, la utilización de las redes sociales, el Internet y los teléfonos smartphone. Los anteriores elementos fueron centrales para lograr que las demandas y acciones tuvieran un impacto transnacional, lo que desarrolló, así, un tipo de militancia global (Tilly \& Tarrow, 2015). 
Siguiendo estos antecedentes, podemos preguntarnos ¿cómo es posible sostener una trayectoria militante más allá de una militancia distanciada?, ¿cuáles son los factores que permiten sostener el compromiso más allá de una demanda específica?, ¿cómo es posible pasar de una participación cívica a un compromiso político?

Es posible encontrar respuesta a estas preguntas a partir del estudio del compromiso político (Fillieule, 2001). Este concepto se incorporó en los análisis de la militancia porque no implicaba homogeneidad ni exclusividad; por el contrario, el sujeto podía establecer múltiples compromisos y esos compromisos podían aumentar, disminuir o desaparecer, principalmente, al estar afectados por aquellos momentos de ruptura en la biografía de los militantes. Los momentos de continuidad o ruptura del compromiso pasaron a formar parte de hitos fundamentales en el estudio de la militancia (Lafont, 2001).

En este sentido, para comprender los niveles de compromiso político y la militancia, no es posible reducir el estudio de la participación política a ciclos de protestas u organizaciones específicas. Los cambios y las nuevas problematizaciones respecto a la militancia obligan a desarrollar un análisis de sus niveles microestructurales ${ }^{6}$ (Fillieule \& Accornero, 2016).

De manera que, este artículo se propone analizar el compromiso político a partir del estudio de las trayectorias militantes al partir de la perspectiva de carrera establecida por Howard Becker. El objetivo principal es dar cuenta de los pasos por los que atraviesa el militante para alcanzar el grado de dirigente, considerando que es ese el momento más elevado de compromiso político, dado que es allí donde aumenta la capacidad para influir dentro del sistema político.

\footnotetext{
6 La diversidad de prácticas que constituye la actividad y el compromiso militante exige a las ciencias sociales desarrollar estudios microestructurales a partir del análisis de trayectorias individuales, con el fin de comprender la militancia como un proceso que puede ser total o parcial, a corto o largo tiempo, y que incluso los militantes cambian de ámbitos o espacios de participación (Fillieule \& Accornero, 2016).
} 


\section{I Adrián Pablo Berardi Spairani}

El análisis de la carrera involucra el estudio y la explicación de cada una de las secuencias que la constituyen, interpretando las continuidades y rupturas entre cada una de ellas, tomando en consideración las contingencias ${ }^{7}$ (Becker, 2012), así como los procesos de ruptura, cambios y afirmaciones en la trayectoria militante. Por su parte, las intercontingencias ${ }^{8}$ (Becker, 2009) se toman como procesos de toma de decisiones a partir de la influencia de terceros.

Si bien cada una de las secuencias mantiene su propia dinámica, una etapa de la carrera es resultado de la anterior y condición de posibilidad de la siguiente; es decir, que una decisión es resultado de decisiones anteriores y condición de las subsiguientes, lo que permite un estudio secuencial del comportamiento. Ahora bien, el estudio de la carrera militante, obliga a comprender y dar cuenta de cada una de las etapas, al considerar los vínculos con los otros y el proceso de aprendizaje dentro de la actividad política, entendiendo la carrera como un proceso dinámico (Fillieule, 2001).

En este sentido, consideramos que la noción de "carrera" (Becker, 2012) constituye una herramienta más sólida para el estudio de la militancia porque permite observar cada etapa y dar cuenta de las motivaciones, intereses, compromisos y contingencias a lo largo del tiempo. Al mismo tiempo, la noción facilita la descripción de los aspectos subjetivos que interpelan al militante, al incorporar una perspectiva de análisis lo suficientemente dinámica para poder contemplar las acciones y los significados atribuidos por los militantes.

Dicho esto, el concepto de carrera resulta más propicio para el estudio de la militancia que la propuesta de análisis desde la perspectiva de trayectoria social (Bourdieu, 2007, 2012). Esta última sugiere que la trayectoria

\footnotetext{
Becker (2012) utiliza este término para referirse a la contingencia laboral, es decir, a los cambios de empleo en la carrera de los individuos dentro del sistema ocupacional. Para fines de este trabajo, se considera contingencia como el momento en el que se produce una ruptura o un cambio profundo en la biografía militante.

$8 \mathrm{Al}$ retomar la perspectiva de Becker (2009), el término intercontingencia nos permite dar cuenta de cómo las decisiones y las acciones que llevan adelante los sujetos están condicionadas por las acciones y las decisiones de las personas con las que se relacionan.
} 
sea entendida dentro de un espacio social específico donde el babitus, como un "sistema de disposiciones duraderas [...] principios generadores y organizadores de prácticas" (Bourdieu, 2007, p. 86), determina y condiciona el recorrido de dicha trayectoria. ${ }^{9}$

Para la metodología de investigación, se optó por un estudio de tipo cualitativo por medio de la historia de vida. Esta técnica, a partir de la construcción de la narrativa del yo, permite mostrar los distintos momentos por los que atravesó el militante a lo largo de su trayectoria, dando lugar al conocimiento de los puntos de inflexión que determinaron su compromiso. Es decir, a partir de su propia narración el militante hace "comprensible su mundo" (Meccia, 2012, p.41), lo que da cuenta de su devenir biográfico, pero también de las relaciones con "sus semejantes y sus entornos sociales" (Meccia, 2015, p. 15), dentro del contexto histórico que describe esa narración (Della Porta, 2014).

Esta perspectiva puede criticarse desde la idea de la ilusión biográfica analizada por Bourdieu (2011), principalmente, en tres aspectos: primero, al considerar la singularidad de la historia de la persona sin tomar en cuenta los condicionantes estructurales. Segundo, al aceptar la trayectoria en una secuencia lineal y cronológica. Tercero, al asumir que la persona no cambia a lo largo de su vida (Bourdieu, 2011). Sin embargo, lo cierto es que tanto la perspectiva de carrera como el uso del relato de vida no conllevan necesariamente a una ilusión; en primer lugar, porque el recorrido de la historia de vida desde la perspectiva propuesta sugiere un análisis de los aspectos objetivos y subjetivos de la trayectoria. Segundo, el recorrido de la carrera militante posee ciertos matices, avances y retrocesos que no constituyen un análisis lineal y cronológico. Tercero, la perspectiva de carrera no da por sentado que las personas y sus decisiones sean inalterables,

\footnotetext{
$9 \quad$ En este sentido, "el principio de las diferencias entre los habitus individuales reside en la singularidad de las trayectorias sociales, a las cuales corresponden series de determinaciones cronológicamente ordenadas e irreductibles las unas a las otras: el habitus que, en función de estructuras producidas por las experiencias anteriores, estructura en cada momento las experiencias nuevas que afectan a esas estructuras en los límites definidos por su poder de selección, realiza una integración única, dominada por las primeras experiencias, de experiencias estáticamente comunes a los miembros de una misma clase” (Bourdieu, 2007, p. 98).
} 
más bien sugiere comprender momentos de contingencias o rupturas que alteran la lógica secuencial de la trayectoria e influyen en la forma de ver el mundo del militante y, por ende, que modifican, también, la vida del sujeto.

Para cumplir con los objetivos propuestos se analizaron tres trayectorias de dirigentes políticos que comenzaron a involucrarse en la participación política en la década del 2000 y que militan en distintas organizaciones políticas:

1) Marisol es Licenciada en Administración de Empresas; en su primera experiencia militante se vinculó a la militancia social cristiana en 2004. En la actualidad es la responsable política de La Cámpora de Jujuy.

2) Luciana es Licenciada en Comunicación Social y comenzó su participación política en 2005 como voluntaria en la organización Juanita Moro. Es integrante de la agrupación HIJOS, regional Jujuy, y en 2015 fue electa Secretaria de Comunicación de la Asociación de Trabajadores del Estado, seccional Jujuy.

3) Marcos comenzó a militar en 2004, primero, al vincularse a las actividades electorales dentro de la Unión Cívica Radical (UCR) y, luego, al iniciar una militancia social ecológica en ECOCLUBES. Fue asesor de un legislador provincial y Coordinador de Políticas de Juventud en la municipalidad de San Salvador de Jujuy.

Complementariamente, se utilizaron entrevistas y charlas informales con distintos militantes y dirigentes políticos. ${ }^{10}$

\footnotetext{
10 Las entrevistas y relatos que integran este artículo forman parte del trabajo de campo realizado en la provincia de Jujuy, Argentina, en el marco de mi tesis doctoral "El mundo militante en la democracia argentina contemporánea. Un estudio de trayectorias militantes en la provincia de Jujuy", realizada entre los años 2014 y 2017. Los nombres de los militantes fueron alterados a fin de preservar su identidad.
} 
Por último, la selección de militantes de diferentes organizaciones tiene como fin poder comprender la militancia más allá de los espacios de pertenencia o ciclos específicos de protesta. Lo anterior permite percibir la militancia, más allá de la estructura de participación, como un tipo de actividad que, a pesar de ser colectiva, involucra decisiones individuales que, incluso siendo así, están condicionadas por un contexto más amplio que el espacio de participación. También permite comparar los distintos desarrollos de las historias militantes para comprender los puntos en común que poseen cada una de las trayectorias, y de esta forma dar cuenta de una carrera militante que les es común a partir de la similitud en cada una de sus secuencias (Berardi, 2017).

\section{Contexto en que se inscriben las trayectorias analizadas}

Las trayectorias militantes que aquí se analizan tienen en común el periodo de inicio de su participación militante en la década del 2000; principalmente el ciclo kirchnerista (2003-2015).

Durante esos años, la Argentina atravesó dos etapas: la primera caracterizada por una fuerte crisis de representación (Torre, 2003) en un marco de crisis económica, con un importante crecimiento del desempleo y la pobreza (Schorr \& Wainer, 2005; Varesi, 2014). El ciclo 2000-2003 se enmarca en el aumento sustancial de la protesta social, con movilizaciones y cortes de ruta en todo el país (Schuster et al., 2006), y cierra con los sucesos del 19 y 20 de diciembre de $2001^{11}$ y con la presidencia provisional de Eduardo Duhalde. Así inició una segunda etapa política y económica, a partir de 2003, con el triunfo de Néstor Kirchner.

Desde lo político, hubo una importante trasformación de los clivajes. El partido político gobernante, Frente para la Victoria (FPV), consolidó su hegemonía política y electoral, y se conformó como un "armado pluralista y transversal” (Mauro, 2014, p. 182) que integró sectores del

11 Sobre los sucesos del 19 y 20 de diciembre de 2001 ver Pereyra, Vommaro, y Pérez (2013). 
Partido Justicialista, grupos de la UCR (Sidicaro, 2011), movimientos sociales y organizaciones de derechos humanos. Al mismo tiempo, incentivó la conformación de nuevos sectores, y espacios políticos, militantes de la juventud (Vázquez \& Vommaro, 2012), entre los que se destacó la organización La Campora.

Por otra parte, los sectores opositores (a lo largo del periodo 2003-2015) conformaron distintas alianzas — principalmente electorales-con variada representación político electoral. Sus distintas voces comenzaron a tener más repercusión luego del año 2008, principalmente, a partir del conflicto con los sectores agropecuarios ${ }^{12}$ y el triunfo en las elecciones legislativas de 2009. En tanto, en el ámbito no electoral ganaron el apoyo y acompañamiento de los medios de comunicación concentrados.

En el plano electoral, el FPV ganó las elecciones de 2005, 2007, 2011 y 2013, así como perdió los comicios intermedios de 2009 al producirse una fractura dentro del peronismo, permitiendo la consolidación de una nueva oferta electoral peronista no kirchnerista (Mauro, 2011). Esta, sin embargo, no puso en cuestión la hegemonía del FPV.

En el plano económico, luego del default del año 2001, la Argentina inició un proceso de crecimiento basado en dos variables: por un lado, aprovechó las ventajas comparativas con los bienes exportables (principalmente commodities) y, por otro, motorizó la demanda y consumo interno (Fernández Bugna \& Porta, 2007), incluso a partir de programas sociales, subsidios a ciertos servicios y planes de empleo, en los que el Estado jugó un papel central respecto a la intervención directa de la economía.

En otros aspectos, la gestión kirchnerista promovió un conjunto de leyes y normativas que tendió a generar igualdad dentro de la sociedad, entre ellas la ley de género, de matrimonio igualitario o las nuevas normativas vinculadas al trabajo rural o al empleo de personal doméstico. $\mathrm{Al}$ mismo tiempo que incentivó el desarrollo del sistema científico y universitario como forma de avanzar en el modelo económico.

12 Para más información sobre este tema ver Varesi (2014). 
En la provincia de Jujuy, ${ }^{13}$ en la que se desarrollan las trayectorias que aquí se presentan, a partir de la década del 2000 también se inició un proceso de estabilidad política e institucional de la mano del gobierno de Eduardo Fellner, luego de más de diez años de crisis política e ingobernabilidad (Lagos \& Gutiérrez, 2009). A lo largo del periodo, el Partido Justicialista (PJ) de la provincia (que integró el FPV) mantuvo la hegemonía tanto en el poder ejecutivo como en el legislativo, y con la promoción de políticas sociales del gobierno nacional logró cierta estabilización con relación a la pobreza.

Respecto al posicionamiento político, dos partidos consolidaron sus disputas, el PJ y la Unión Cívica Radical (UCR) de Jujuy (que ensayó distintas alianzas electorales a lo largo de los años sin obtener triunfos). Si bien hay un sector del peronismo que se desprendió del PJ y que configuró un nuevo espacio político-electoral, el Frente Primero Jujuy, no logró sacar ventajas sobre el PJ y su competencia terminó siendo contra la UCR.

La novedad del ciclo fue la conformación del Partido por la Soberanía Popular (SPS), brazo político de la Organización Barrial Tupac Amarú ${ }^{14}$ e integrante del Frente Unidos y Organizados por la Soberanía Popular $^{15}$ (FUyO), como tercera fuerza electoral de la provincia. Su participación electoral se configuró como opositora al gobierno provincial del PJ, pero como aliado al ejecutivo nacional y logró obtener cuatros escaños en la Cámara de Diputados Provincial en las elecciones intermedias de 2013.

\footnotetext{
13 Para conocer el contexto y el desarrollo de los clivajes políticos en la provincia de Jujuy ver Berardi (2017).

14 La Organización Barrial Tupac Amarú surgió en 1998 como la pata barrial de la Central de Trabajadores Argentinos (CTA). Sin embrago, a partir de 2003, y beneficiada por el Programa de Emergencia Habitacional, se independizó y se consolidó como una de las mayores organizaciones del país. Sobre cuáles fueron las condiciones gracias a las que surgió y se consolidó la Organización Barrial Tupac Amarú ver Battezzati (2012), Moscovich (2013), Tavano (2015) y Berardi (2016).

15 Integrado por sectores kirchneristas, no del PJ de Jujuy (Berardi, 2017).
} 
Esta situación reconfiguró la relación de fuerzas en el Poder Legislativo provincial, principalmente porque los votos obtenidos por el FUyO provenían de sectores que antes eran afines al PJ jujeño, lo que terminó favoreciendo a la UCR que, por primera vez desde 1983, obtuvo la misma cantidad de diputados provinciales que el PJ, rompiendo así una hegemonía de treinta años. ${ }^{16}$

\section{Primera Etapa: la iniciación militante}

Militar parece ser una decisión íntegramente personal, generada por la motivación individual y psicológica a partir de la cual los sujetos se involucran en la participación política o en los asuntos públicos (Verba, Schlozman \& Brady, 1995). Sin embargo, la decisión de participar en política no determina la posibilidad de hacerlo. Es posible observar un conjunto de factores externos a los sujetos que son realmente fundamentales para iniciar un compromiso político: las redes interpersonales (o redes sociales), los clivajes políticos y la oferta de participación.

Las redes interpersonales o redes sociales (Diani, 2004) constituyen un conjunto de vínculos, interacciones y conexiones que establecen y construyen al sujeto (inicialmente relacionado con las relaciones afectivas ya sean familiares, de amistad o vecindad). Estas están conformadas por la articulación de los lazos sociales que permiten un intercambio influyente para el involucramiento militante, convirtiéndose en facilitadores de la participación política (Diani, 2004; Della Porta \& Diani, 2011; McAdam, 1982, 1988; Passy \& Giugni, 2000; Passy, 2002; Lafont, 2001; Poupeau, 2007). Al mismo tiempo, funcionan como estructuras que permiten crear oportunidades de participación, elaborar canales de solidaridad y fomentar la construcción de identidades colectivas (Kitts, 2000).

\footnotetext{
16 El único momento en el que el partido de gobierno de la provincia no tuvo mayoría en la Cámara de Diputados fue en el periodo 2013-2015, cuando tanto el oficialismo como la oposición poseían diez bancas cada uno, en tanto que el FUyO, constituido como tercera fuerza provincial, tenía cuatro bancas (Berardi, 2017).
} 
Estas redes no son estáticas y, en cierto punto, su producción y reproducción es un elemento clave a lo largo de la carrera militante; es decir que son productoras y producto de la participación (McAdam, 1982; McClurg, 2003; Kenny, 1992; \& Klandermans \& Oegema, 1987) y permiten comprender que los sujetos no toman decisiones aislados, sino que lo hacen insertos en el contexto en el que interactúa (Della Porta \& Diani, 2011).

Por otro lado, los clivajes políticos y la oferta de participación están determinados por el contexto sociopolítico en el que el sujeto inscribe su participación. Las fracturas, desarticulaciones y surgimientos de nuevos espacios de participación, determinan las posibilidades de involucrarse en la política; pero también los ciclos de protesta, los procesos electorales y las crisis político-económicas establecen disponibilidades y disposiciones que permiten acercar o alejar al sujeto de los ámbitos de militancia.

De esta forma, los cambios o (re)definiciones de clivajes políticos operan como articuladores de identidades e intereses políticos, y producen rupturas o confluencias (Canelo, 2001) en las motivaciones, y posibilidades, que influyen e impactan en el momento del involucramiento militante. Esas redefiniciones afectan directa o indirectamente en la oferta de participación y configuran nuevos ámbitos de involucramiento político en los que las motivaciones políticas intervienen.

Los clivajes ejercen, entonces, un doble proceso de influencia: facilitan la emergencia de nuevos espacios de participación o alteran las condiciones de los ya existentes, dando lugar al ingreso de nuevos militantes. También motivan o desmotivan el proceso de involucramiento, ponderando el peso político de cada uno de los ámbitos de militancia dentro de cada uno de los contextos políticos. Por otra parte, esas transformaciones en los clivajes están sujetas a la estructura de oportunidades políticas (Tarrow, 1997), en tanto estas debilitan las alianzas entre las élites y abren nuevas oportunidades de acceso al sistema político. 


\section{Marisol}

Marisol es dirigente de la organización política La Campora. De familia peronista y con un abuelo que fue diputado, Marisol comenzó a militar en la década del 2000, pero:

[durante la década de 1990] participé de las tomas de los colegios, pero desde un lugar no [de] conciencia social [...]. Yo ni siquiera dimensionaba [...] porque yo también estaba embebida con esto de 'no me importa la política', pero sí me movilizan y sí me sensibilizan las injusticias (Marisol, La Campora, diciembre de 2015).

Nacida en San Salvador, provincia de Jujuy, realizó su carrera universitaria en la provincia Córdoba donde se vinculó a la militancia social cristiana a partir del contacto con una compañera de la facultad: "empiezo como una militancia social, cristiana, desde la religión, y me comprometo mucho, para mí fue una etapa que me marcó muchísimo, [...] todos los sábados íbamos a la villa" (Marisol, La Campora, diciembre de 2015).

Sin embargo, la situación que podía observar en la villa (la pobreza, la miseria, la falta de oportunidades) fue un factor clave para su conversión a una militancia partidaria; en este sentido Marisol comenzó a preguntarse:

¿Y cuál es la solución?, modificar la ley, la política, y fue ahí como el primer quiebre de darme cuenta que la única manera de transformar la realidad y de modificar estas cosas era a través de la política. (Marisol, La Campora, diciembre de 2015).

En el año 2012, motivada por el gobierno de Cristina Fernández de Kirchner ${ }^{17}$ y por el contacto de una amiga, se integró a la organización

\footnotetext{
17 Cristina Fernández de Kirchner fue presidenta de la Argentina en dos periodos entre los años 2007 y 2011. Provenientes del Partido Justicialista (PJ), Néstor Kirchner (presidente de Argentina entre 2003 y 2007) y Cristina Fernández conformaron desde 2003la alianza "Frente para la Victoria" integrada por distintas organizaciones y partidos políticos, incluida la Unión Cívica Radical.
} 
La Campora de Jujuy, creada al calor del gobierno nacional de ese momento.

Algunos dirigentes del PJ sostenían que Cristina Fernández promovió la creación de organizaciones propias en desmedro del partido:

Creo que Cristina sí dejó un poco de lado el peronismo, creó su propio frente, $[\ldots]$ creó sus propias organizaciones, como fue La Cámpora, como fue Kolina [...]. Ella lo necesitaba, formar un cuadro de alguna manera de contención hacia ella (Martín, PJ, septiembre de 2016).

En tanto, otros militantes, sobre todo provenientes de las generaciones más jóvenes, afirman que el kirchnerismo permitió el ingreso de los jóvenes a la militancia política:

La oportunidad de poder hablar [para los jóvenes] es algo que se empezó a generar a partir de las reivindicaciones que vino a hacer Néstor [Kirchner]. Cuando [él] llegó todos queríamos que se vayan todos; es más, todos los políticos eran ladrones (Natalia, Juventud Peronista, septiembre de 2016).

\section{Luciana}

En 2015, Luciana se integró como voluntaria en la Organización Social Juanita Moro, ${ }^{18}$ donde fue convocada para trabajar en el Área de Prensa por ser estudiante de Comunicación Social. Luego de un tiempo, comenzó a participar de otras actividades y se sumó a la campaña de alfabetización que llevaba adelante la organización. Su expertise (Vecchioli, 2012) como futura comunicadora social le permitió ir involucrándose en la participación política.

\footnotetext{
18 Según su página web de la Organización Social Juanita Moro, la organización surgió en 1987 como "respuesta a la demanda de necesidades básicas de la población, especialmente del área mujer" (Organización Social Juanita Moro, parr. 1), con el objetivo de "superar la discriminación contra la mujer y promover las condiciones sociales para garantizar el ejercicio efectivo de los derechos de la mujer" (Organización Social Juanita Moro, parr. 2).
} 
Su trabajo como comunicadora también la acercó a la organización Hijos e Hijas por la Identidad y la Justicia contra el Olvido y el Silencio (HIJOS) en Jujuy, ${ }^{19}$ en la que empezó a militar (a pesar de no ser familiar de desaparecido) y en la que llevó adelante actividades en el Área de Prensa. ${ }^{20}$ Para Luciana ambos espacios le permitieron acercarse y conocer distintos conflictos sociales, lo que constituyó un "aprendizaje muy importante" para su militancia sindical.

Un tiempo después, Luciana comenzó a trabajar como en el Área de Prensa en el Instituto Nacional contra la Discriminación, la Xenofobia y el Racismo (INADI), y desde ese momento se involucró a la militancia sindical:

En 2007 yo me afilio a ATE [Asociación de Trabajadores del Estado]. Yo trabajaba en el INADI, en Prensa, y empecé a tener problemas con mi jefa [...]. Entonces me acerqué a ATE por eso. Yo ya conocía ATE desde antes, porque estaba haciendo un documental sobre la historia de ATE Jujuy [...]. Empiezo a participar en las marchas, en algunas actividades gremiales, bueno, empecé a adherirme a los paros nacionales (Luciana, ATE, junio de 2015).

La Asociación de Trabajadores del Estado (ATE) no solamente es uno de los principales espacios sindicales de la provincia de Jujuy, sino que fue, junto con los gremios docentes, un espacio de resistencia de las políticas de ajuste durante las décadas de 1980 y 1990 (Lagos \& Gutiérrez, 2009).

\section{Marcos}

Marcos, militante de la Unión Cívica Radical (UCR) de Jujuy, sostiene que comenzó a militar de adolescente como un juego:

\footnotetext{
19 Hijos e Hijas por la Identidad y la Justicia contra el Olvido y el Silencio (HIJOS) es una organización de derechos humanos conformada en 1995, con regionales en distintas partes de la Argentina.

20 Luciana había realizado un documental sobre los militantes de la Asociación de Trabajadores del Estado (ATE) de Jujuy, desaparecidos durante la última dictadura militar y este trabajo le permitió vincularse con la hija de uno de esos militantes y principal dirigente de HIJOS Jujuy, quien no dudó en invitarla a sumarse a la organización.
} 
La verdad [empecé a militar] porque había un vecino en todo esto que nos llevaba, nos decía "vengan chicos, necesito ir a pegar unos afiches, necesito hacer esto", cosa que él nos llevaba. Nosotros íbamos contentos; nos convidaban gaseosa, nos daban algo para comer, unos sándwich. La verdad que después me empezó a gustar, te intriga, te llama todo esto de la militancia, y empezás... yo tenía ya mi familia... eran radicales pero no eran militantes fervientes [...], entonces la verdad que todo eso empezó a que yo vaya a ir a las reuniones de la Juventud, las reuniones de los mayores, y como que todo te empezó a llegar" (Marcos, UCR, septiembre de 2016).

Si bien es cierto que la UCR a nivel nacional quedó debilitada luego de la presidencia de Fernando de la Rúa (1999-2001), que terminó con un estallido social en diciembre de 2001, producto de un fuerte descontento social, en la provincia de Jujuy el partido logró sostener altos niveles de representación e incluso alcanzó la intendencia de la Ciudad de San Salvador, capital de la provincia, de la mano de Raúl Jorge.

Respecto a esto, un dirigente de la Juventud Radical (JR) y actual funcionario del gobierno de Jujuy sostuvo:

[...] nosotros [la juventud] hicimos un clic en el año 2007, cuando ganamos la intendencia de la ciudad de San Salvador de Jujuy [...]. Nosotros nos militamos todo, recorrimos todos los barrios de acá. Era un partido que no tenía ni la intendencia ni el gobierno, teníamos que hacer algo, bueno, nos hicimos fuertes en capital, militamos, ganamos la ciudad (Pablo, JR-UCR, septiembre de 2016).

En esta etapa, las trayectorias muestran la forma en que los militantes se involucran en los espacios de militancia; se puede observar cómo los vínculos sociales y los intereses personales se relacionan con la oferta de participación disponible determinados por los clivajes políticos. 


\section{Segunda Etapa: aprendizaje y afirmación de compromisos}

Como sostuvimos, las redes interpersonales son fundamentales para el involucramiento, pero también forjan un conjunto de significados que influye en la percepción del sujeto sobre el mundo social, configuran procesos de aprendizaje y producen el establecimiento del compromiso ${ }^{21}$ político (Passy \& Giugni, 2000; Lafont, 2001; Poupeau, 2007) incentivando la participación y su continuidad a lo largo del tiempo. Por esto, una vez que el sujeto se incorpora a un espacio de militancia establece un proceso de aprendizaje a partir de la asimilación de normas, prácticas y rutinas militantes. Si bien es el momento en que los viejos militantes ejercen un proceso de influencia sobre los ingresantes, también la propia participación se convierte en un proceso de conocimiento.

El aprendizaje se configura a partir de un conjunto de experiencias que establece una lógica militante, lo que garantiza la continuidad y la coherencia en las acciones de militancia. Desde la perspectiva de Becker (2012), el aprendizaje se produce al compartir prácticas con personas experimentadas. Así, un militante que se inicia produce un proceso de aprendizaje al participar con otros militantes que ya tienen un marcado recorrido dentro de la militancia.

Si bien, el aprendizaje, es un proceso que atraviesa toda trayectoria militante, se convierte como prioritario en esta etapa, porque construye un conocimiento sobre la cultura de la militancia, el quehacer militante y las normas que determinan este tipo de prácticas.

En la militancia, el aprendizaje se convierte en una actividad colectiva que favorece los intercambios y permite la (re)elaboración constante de las prácticas, y la conformación de nuevas redes interpersonales (lealtades, solidaridades y recursos), que se generan en la misma

\footnotetext{
21 Simon (2011) y Dubet (1989) sostienen que el compromiso, producto de las actividades grupales, permite la configuración de una identidad colectiva que incentiva la participación política.
} 
práctica militante. Estas nuevas redes funcionan también como un elemento persuasivo dentro de las organizaciones, como un factor motivacional que fomenta la participación (Klandermans, 1984) y su sostenimiento en el tiempo.

\section{Luciana}

Luciana cuenta que la presencia de los dirigentes tradicionales del gremio fue fundamental para el aprendizaje, pero que el militante nutre su conocimiento a partir del propio trabajo político:

Yo acompañaba las actividades, así que yo cuando podía iba y estaba, digamos, todos los días yo iba un ratito, viste, para ayudar a los chicos a hacer un volante, a qué sé yo; siempre estaba, digamos, tratando de participar, de aprender. Y después fui delegada [del lugar donde trabajaba] y después me fui metiendo más, más y más, y empecé a estar más tiempo en el gremio, a meterme más en lo que es la militancia sindical y qué sé yo, y bueno [...]. Ya de ahí estaba metida de lleno, digamos, militando en ATE [...]. En ATE es así todo el tiempo, es activo. [...], porque hay un montón de cosas para hacer, y cuando uno le agarra, viste, empezás y empezás. Y es un gremio que ha estado siempre en la calle, acá en Jujuy siempre se ha caracterizado por ser el gremio más combativo, digamos.... [...] asumís un compromiso que no podés cancelar (Luciana, ATE, junio de 2015).

La idea de un gremio que se identifica por la acción directa en la vía pública constituye para Luciana uno de los principales puntos de su compromiso y aprendizaje político, sobre todo, cuando los propios dirigentes del sindicato sostienen y reproducen esa idea:

Tuvimos mucha lucha, seguimos teniéndola actualmente; [...] ATE es el gremio más grande acá [...], acá se pelea, ganamos o empatamos, pero perder no, [...] hasta ahora no hemos perdido (Raúl, exsecretario general de ATE Jujuy, septiembre de 2016). 
Se trata de poner el cuerpo por lo que uno cree. Hay que poner el cuerpo para pelear, [...] uno todo lo que hace es para poder ganar, y vos no ganás si no peleás (Juan, dirigente de ATE Jujuy, junio de 2015).

\section{Marisol}

Para Marisol, esta etapa además estuvo acompañada por un cambio de espacio de participación. Su militancia social la llevó a darse cuenta de que la problemática de la injusticia y la pobreza debe transformarse desde espacios de poder:

[...] me empecé a preguntar ¿y cuál es la solución?, modificar la ley... la política, y fue ahí como el primer quiebre de darme cuenta que la única manera de transformar la realidad y de modificar estas cosas era a través de la política. [...] Yo venía con un compromiso social que no tenía que ver con la política [...]; no me interesaba la política. [...] Me cuestionaba: estoy en el lugar equivocado, pero cuál es el lugar correcto. [Finalmente] en 2012 vuelvo [a Jujuy] con una decisión de militar en La Campora [...] simplemente porque yo sentía que lo que a mí me representaba era el proyecto nacional y popular [...] era Néstor y Cristina, y [...] que La Campora era el espacio (Marisol, La Campora, diciembre de 2015).

El involucramiento en esta organización significó para ella un proceso de compromiso, su identificación con el kirchnerismo la había diferenciado de sus amigos y compañeros de la militancia social.

Un militante del pj de Jujuy resume así el efecto del kirchnerismo para los jóvenes que se involucraron en la política durante los gobiernos de Néstor Kirchner y Cristina Fernández de Kirchner:

Siempre estuve involucrado en la política de alguna u otra manera, [pero] con esas ganas de militar, de meterse de lleno a la calle, de escuchar a los compañeros, de escuchar reuniones, de asistir a 
distintos lugares, y eso sí lo logré gracias a Néstor Kirchner (Luis, PJ, septiembre de 2016).

\section{Marcos}

Por su parte, Marcos combinó su actividad en la UCR con un activismo ecológico por fuera del partido, en una organización denominada ECOCLUBES. Si bien los jóvenes del partido tenían una fuerte participación en las campañas electorales, su experiencia con la ecología le permitió involucrarse como asesor de un diputado provincial: "Yo trabajaba con un concejal en la municipalidad [...] yo lo asesoraba en todo lo que era la ecología, generando actividades con el tema ecológico" (Marcos, UCR, septiembre de 2016).

El trabajo con el concejal, según Marcos, fue un punto central para comenzar a militar más allá del aspecto electoral, y para formar su propia línea dentro de la juventud del partido, al establecer nuevos vínculos:

Yo me separo [del concejal] y junto con otros compañeros empezamos un grupo aparte [...] después se sumaron otros grupos más, [al] presidente de la Juventud provincia en ese momento, y desde ahí ya empezamos a manejar la Juventud [radical de la] provincia (Marcos, UCR, septiembre de 2016).

En ese sentido, el trabajo con el concejal no solo le permitió acceder a un aprendizaje, sino que, además, garantizó que accediera a nuevos contactos y construir una red interpersonal propia dentro del mundo militante; así se refiere al tema un militante del PJ:

Cuando comenzás a militar cerca de algún dirigente que está en algún cargo, uno ya va haciendo pasos más firmes; te abre un poco el camino dentro de lo que es el partido, [...] y tejés relaciones con la gente que asiduamente va al partido, [...] Entonces, bueno, ahí se fueron tejiendo otros lazos, y me involucré ya más un poco en lo que era la militancia (Nicolás, PJ, marzo de 2016). 
En esta segunda etapa, se construye un puente. Se trata de un momento de confluencia entre un proceso de intercambio con otros militantes, la incorporación de rutinas y normas militantes y el establecimiento de un tipo de compromiso producto de la propia práctica. Una etapa en donde el militante desarrolla un proceso de reciprocidad y configura nuevas redes interpersonales, lo que genera un proceso de reconocimiento tanto interno como externo del mundo militante (Berardi, 2017).

\section{Tercera etapa: la construcción política}

Esta etapa determina el proceso por el cual el militante decide profundizar su compromiso; constituye una búsqueda personal de status y reconocimiento público, y tiende a establecer un proceso de profesionalización de la militancia.

En este sentido, se entiende que la construcción política constituye un elemento de acceso al poder real, es decir, la ocupación de espacios de decisión (tanto en la organización de pertenencia como dentro de las estructuras estatales) o la influencia en el Estado. Esta construcción política se alcanza a partir del reconocimiento público y status militante, es decir, cuando se alcanza un grado de dirigente dentro del espacio (Berardi, 2018).

Esta etapa es, entonces, un momento en el que consolidado cierto nivel de compromiso, el militante tiende a producir las condiciones para subsistir dentro del mundo militante (Berardi, 2017). Esta etapa se convierte en una secuencia en la que la construcción de redes interpersonales de las etapas anteriores le permite al militante garantizar lealtades y acceder a recursos.

\section{Marisol}

Cuando Marisol ingresó en La Campora, pasó inmediatamente a formar parte del Frente de Profesionales. Sin embargo, esto le generó muchísimas controversias en tanto no estaba acostumbrada a lo que 
ella denomina "la rosca política". Entonces se resguardó en su expertise como forma de hacerse camino en la organización:

Había empezado a trabajar en la provincia, en el Ministerio de Producción, [...] para el sector de la agricultura familiar. Yo era la responsable financiera [...] y hacíamos proyectos y se subsidiaba [...] a proyectos productivos que tenían que ver con organizaciones de la ruralidad (Marisol, La Campora, diciembre de 2015).

Por medio de los contactos que generó su propia actividad en el ministerio y reclutando militantes que tenían poca participación en la organización, e incluso amigos que no eran militantes, logró conformar el Frente Rural de la organización, y paralelamente coordinar la "Red Comprar"22 en Jujuy. Desde su perspectiva, la conformación del Frente Rural llevó a que muchos militantes pasivos comenzaran a involucrarse más activamente. En este punto, la construcción del espacio de militancia se marcó con la premisa de:

Generar otros vínculos de compañerismo. [...] Creo que es la fortaleza del Frente, de haber demostrado a todos, $[\ldots]$ otra manera de construir, otra manera de construir en el territorio, otra manera de construir con los compañeros, otra forma de militar, otra forma de gestionar [...]. Empezamos a comprender este proceso que nos pasó, $[\ldots]$ cualquier espacio que vos empezás, ya sea político o no político, cualquier espacio que uno empieza nuevo, necesitas primero sentirte parte, después [de] que te sentís parte, porque en algún punto te sentís cómodo, con los compañeros, con el lugar, con la situación, con la construcción, con el espacio específico de construcción, que es el primer paso. El segundo paso es, bueno, una vez que te sentís parte eso se tiene que traducir [...] de a poco en mayor compromiso, y ese mayor compromiso tiene que ver con

\footnotetext{
22 La "Red Comprar" funcionó como un programa dependiente de la Secretaria de Comercio Interior de la Nación. Su objetivo era garantizar precios accesibles para productos de consumo masivo y garantizar el ingreso al mercado de mercaderías de segundas marcas principalmente producidas por pequeños emprendimientos y cooperativas. La red estuvo presente en varias provincias, entre ellas, Chaco, Mendoza, Jujuy y San Luis (Gustavo Sylvestre, 2014).
} 
algo que es $[\ldots]$ que cualquier persona militante de a poco en un proceso más largo [...] va dejando lo individual por lo colectivo (Marisol, La Campora, diciembre de 2015).

Poco tiempo después, Marisol se convirtió en referente de la organización en la provincia de Jujuy y en 2017 fue candidata a concejal de San Salvador de Jujuy.

\section{Luciana}

Luciana sostiene que desde el momento en que comenzó su militancia en ATE asumió un tipo de compromiso que no pudo cancelar. Fue delegada en sus distintos espacios de trabajo y participó en distintas elecciones del gremio y llegó a ser secretaria de Prensa en 2015. Para ella: "Que te den esa responsabilidad es un reconocimiento de los compañeros, [...] es un reconocimiento, que uno siente eso, además de una responsabilidad muy grande, un reconocimiento al laburo" (Luciana, ATE, junio de 2015).

En este sentido, Luciana lee su status militante como una responsabilidad y, al mismo tiempo, como un logro dentro de su militancia. Ella insiste en que forma parte del devenir de un compromiso activo, de estar en el día a día, de poner el cuerpo y luchar por sus compañeros. Se trata del fruto de la propia práctica; no una decisión, sino un devenir, "es sui generis":

Hoy, la militancia ya se ha juntado con la práctica, con el sentimiento, con todo, porque uno como que va volcando y organizando tu vida también cotidiana con respecto a la militancia. [...] Entonces es como que la vida de uno se va organizando en torno a eso; [la militancia] se vuelve el centro de tu vida (Luciana, ATE, junio de 2015). 


\section{Marcos}

En el caso del proceso de construcción política de Marcos, él utilizo su experiencia con un reconocido concejal para iniciar un proceso de reconstrucción de la Juventud Radical (JR) de la provincia de Jujuy:

Nosotros íbamos hablando con cada joven para que se sumen también a nuestra línea, para que se sumen, para que apoyen [...]. En ese momento ganamos la [conducción de la juventud de la] provincia y empezamos a sumar jóvenes, [que] el partido vea que se estaba generando un movimiento aparte y que estás generando justamente, que hay más adhesiones de jóvenes, que comparten las mismas ideas que vos. Entonces... se logró, cómo decirte... que se logró en cierto punto, conseguir recursos, y recorrer casi toda la provincia (Marcos, UCR, septiembre de 2016).

Marcos logró acceder vía elecciones internas del partido a la vicepresidencia cuarta de la JR y posteriormente ganó la presidencia del Comité Capital, al mismo tiempo que fue convocado para ocupar el cargo de coordinador de Política de Juventud en la municipalidad de San Salvador, gobernada por el radical Raúl Jorge.

A partir de los relatos, se puede afirmar que la construcción política aparece dentro de la carrera militante como un lugar de confirmación del compromiso político, pero también como el momento en el que el militante profesionaliza su actividad y accede a recursos que le permiten dedicar tiempo completo a la militancia, es decir, que se convierte en una actividad exclusiva. Esta etapa es la que garantiza la obtención de recursos, solidaridades y, sobre todo, nuevas redes interpersonales que (re)generan el compromiso antes establecido y permiten sostenerlo más allá del tiempo.

\section{Conclusiones}

En este artículo, se propuso discutir la participación política y la militancia a partir del establecimiento del compromiso político. El 
interés se centró en comprender la manera en la que es posible analizar la militancia más allá de las estructuras organizativas, las olas de protestas o la participación política ante ciertas demandas específicas.

En una primera instancia, a partir de las distintas lecturas sobre la militancia actual, se pudo constatar que la militancia integral parece haber perdido espacio dentro del proceso de participación política y que, por contrario, se profundizó un tipo de militancia más distanciada o puntal que se asemeja al activismo más que al involucramiento político dentro de una organización.

Partiendo de este supuesto, la pregunta que orientó este trabajo fue cómo debía analizarse la militancia en el mundo contemporáneo. Por medio del estudio de un conjunto de trayectorias militantes pudimos dar cuenta que el compromiso político constituye un punto clave para el entendimiento de la militancia, y que, en todo caso, la continuación de ese compromiso a lo largo del tiempo es lo que nos permite pensar en la idea de carrera militante, es decir en una militancia no distanciada.

El estudio de la carrera militante permitió establecer un conjunto de pasos o secuencias que atraviesa el militante a lo largo de su trayectoria; esas etapas son comunes a todos los militantes y es posible visualizarlas a partir del análisis de las historias de vidas de los militantes entrevistados. Es decir, que las etapas no fueron propuestas ad hoc, sino que los propios militantes en sus relatos dieron cuenta de ello. Esto, sin duda, no significa que las trayectorias militantes sean lineales; por el contrario, en algunos casos podemos observar trayectorias errantes, en las que los militantes abandonan su compromiso político y lo retoman en otro momento.

A partir de estas secuencias, fue posible identificar cómo el militante logra consolidar su compromiso político a lo largo del tiempo más allá de su participación en ciertas acciones militantes o demandas específicas. Por medio de este análisis, se pudo observar que la etapa de iniciación es común a todo tipo de militancia o activismo: es un momento en el que las motivaciones, los contextos y las redes permiten establecer algún tipo de compromiso. Ese puede ser puntual, 
por una causa específica y por un plazo determinado, lo que significa que un activista puede involucrarse en un tipo de actividad militante y luego abandonarla y alejarse de la práctica política.

Es, entonces, en la segunda etapa en la que se afirma el compromiso a partir del proceso de aprendizaje y los vínculos con otros militantes experimentados. Es en ese momento en el que el activista decide continuar con su actividad política. En esta etapa, los procesos de influencia, los compañeros de militancia, la incorporación de las lógicas militantes parecen ser factores que atan al militante a afianzar compromisos superando la primera instancia. A su vez, si ese involucramiento logra superar las dificultades que la propia militancia genera (diferencias internas, falta de motivaciones o exclusiones por parte de otros militantes, falta de vínculos dentro del espacio de participación, cuestiones familiares o laborales que limiten el tiempo de participación) será posible establecer una tercera etapa, "la construcción política".

La construcción política es el momento en que el compromiso asumido requiere de una profundización del involucramiento en las estructuras de participación, y se inicia un proceso de profesionalización de la militancia por medio de acceso a recursos y cargos. En esta etapa el militante comprende que su participación política solo es posible de sostener en la medida en que la propia militancia produzca las condiciones para su reproducción y mantenimiento. Es el momento en que el militante comprende que para alcanzar el objetivo final de influir en el sistema político, su carrera depende de poder avanzar dentro de las propias estructuras de participación.

El proceso de construcción política tiene el objetivo de alcanzar la ocupación de espacios de decisión o influencia en el Estado e, incluso, podría pensarse como la última etapa de una carrera militante exitosa. Aquí el militante logra integrar el sistema político en su totalidad, lo que constituye un factor clave para influenciar a los recién iniciados y reafirmar su compromiso político. Es el momento en que el militante se convierte en dirigente político. De esta forma, las secuencias aquí presentadas permiten pensar en la carrera militante y el establecimiento del compromiso político más allá de un activismo puntual o de 
una militancia distanciada. Lo anterior no significa que el militante no pueda abandonar su compromiso en cualquier momento; sin embargo, da cuenta de qué factores pueden sostenerlo a lo largo del tiempo.

Si bien no fue un objetivo que se planteó en este trabajo, no se debe olvidar que la militancia es una actividad dinámica que llevan adelante los sujetos y que sus vidas se encuentran atravesadas por otros factores, familiares, de salud, laborales, etc., que pueden influir en el abandono del compromiso. Esta situación constituye una variable que debe ser analizada en sucesivos trabajos vinculados al estudio de la militancia.

Por otra parte, al constituirse este como un trabajo cualitativo donde el propio militante por medio de su relato reconstruye su vida militante, no es posible pensar que los resultados aquí expuestos constituyan una generalidad; en todo caso, forman parte de un análisis que pretende aportar al entendimiento de la participación política contemporánea, y no aspira a dar por cerrada la discusión respecto a las nuevas (y viejas) formas de militancia.

\section{Referencias}

Abdelali, A. (2013). Wave of change in the Arab world and chances for a transition to democracy. Contemporary Arab Affairs, 6(2), 198-210. https://doi.org/10.1080/17550912.2013.782718

Ayala, L. J. (2000). Trained for Democracy: The Differing Effects of Voluntary and Involuntary Organizations on Political Participation. Political Research Quarterly, 53(1), 99-115. https://doi. org/10.1177/106591290005300105

Battezzati, S. (2012). La Tupac Amarú: Intermediación de intereses de los sectores populares en la provincia de Jujuy. Desarrollo Económico, 52 (205), 147-171.

Becker, H. (2009). Trucos del Oficio: Cómo conducir su investigación en ciencias sociales. Buenos Aires: Siglo Veintiuno Editores.

Becker, H. (2012). Outsider: Hacia una sociologia de la desviación. Buenos Aires: Siglo Veintiuno Editores. 
Berardi, A. (2016). Milagro Sala en la cárcel: Por qué Jujuy, por qué Milagro. Revista Anfibia. Recuperado de http://revistaanfibia.com/ensayo/ porque-jujuy-porque-milagro/

Berardi, A. (2017). El mundo militante en la democracia argentina contemporánea: un estudio de trayectorias militantes en la provincia de Jujuy (Tesis doctoral). Instituto de Altos Estudios Sociales, Universidad Nacional de San Martín. Recuperado de http://ri.unsam.edu. ar/handle/123456789/106

Berardi, A. (2018). Carrera militante y construcción política. Un estudio de trayectorias militantes en la provincia de Jujuy. Revista Cuadernos de la Facultad de Humanidades y Ciencias Sociales, Universidad de Jujuy, (54), 85-114.

Bergel, M. (2011). El anti-norteamericanismo en América Latina (1898-1930). Apuntes para una historia intelectual. Nueva Sociedad, (236), 152-167.

Bergel M., \& Martínez Mazzola, R. (2012). "América Latina como práctica: Modos de sociabilidad intelectual de los reformistas universitarios (1918-1930)". En C. Altamirano (Ed.), Historia de los intelectuales en América Latina: II. Los avatares de la "ciudad letrada" en el siglo XX (pp. 119-145). Buenos Aires: Katz Editores.

Bourdieu, P. (2007). El sentido práctico. Buenos Aires: Siglo Veintiuno Editores. Bourdieu, P. (2011). La ilusión biográfica. Acta Sociológica, (56), 121-128.

Bourdieu, P. (2012). La Distinción. Criterios y bases sociales del Gusto. Buenos Aires: Taurus.

Calhoun, C. (2013). Occupy Wall Street in perspective. The British Journal of Sociology, 64(1), 26-38. https://doi.org/10.1111/1468-4446.12002

Canelo, P. (2001). ¿Dónde está el enemigo?: La rearticulación menemista de los clivajes politicos y la disolución del antagonismo social. Argentina, 1989-1995. Informe final del concurso: Culturas e identidades en América Latina y el Caribe. Programa Regional de Becas CLACsO, 2001. Buenos Aires: Consejo Latinoamericano de Ciencias Sociales (CLACSO) Recuperado de http://biblioteca.clacso.edu.ar/gsdl/collect/clacso/index/assoc/ D3104.dir/canelo.pdf

Carty, V. (2015) The Indignados and Occupy Wall Street Social Movements: Global Opposition to the Neoliberalization of Society as Enabled by Digital Technology. Tamara, 13(3), 21-33.

Della Porta, D. (2014). Methodological Practices in Social Movement Research. Oxford: Oxford University Press. 
Della Porta, D. (2015). Social movements in times of austerity: bringing capitalism back into protest analysis. Cambridge, Malden: Polity Press.

Della Porta, D., \& Diani, M. (2011). Los Movimientos Sociales. Madrid: Centro de Investigaciones Sociológicas (CIS).

Della Porta, D., \& Tarrow, S. (Eds.). (2005). Transnational Protest and Global Activism. Oxford: Rowman \& Littlefield publishers, INC.

Della Porta, D., Andretta, M., Fernandes, T., O’Connor, F., Romanos, E., \& Vogiatzoglou, M. (2017). Late Neoliberalism and its Discontents in the Economic Crisis. Comparing Social Movements in the European. Cham: Palgrave Macmillan.

Deutsch, F. (2009). Participation and Democracy: Dynamics, Causes and consequences of Elite-Challenging Activities (Tesis de doctorado). Escuela de Humanidades y ciencias sociales, Jacobs University. Recuperado de https://opus.jacobs-university.de/frontdoor/index/index/docId/271

Diani, M. (2004). Networks and Participation. En D. A. Snow, S. A. Soule \& H. Kriesi (Eds.), The Blackwell Companion To social movements (pp. 339359). Malden: Blackwell Publishing Ltd.

Dietlind, S., Hooghe, M., \& Micheletti, M. (2005). Politics in the Supermarket: Political Consumerism as a Form of Political Participation. International Political Science Review, 26(3), 245-269. https://doi. org/10.1177/0192512105053784

Dubet, F. (1989). De la sociología de la identidad a la sociología del sujeto. Estudios Sociológicos, 7(21), 519-545.

Elizalde, S., \& Mateo, N. (2018). Las jóvenes: entre la "marea verde" y la decisión de abortar. Salud Colectiva, 14(3), 433-446. https://doi. org/10.18294/sc.2018.2026

Fernández Bugna, C., \& Porta, F. (2007). El crecimiento reciente de la industria argentina. Nuevo régimen sin cambio estructural. En B. Kosacoff, (Ed.), Crisis, recuperación y nuevos dilemas. La economía argentina, 2002-2007 (pp. 63-106). Santiago de Chile: CEPAL.

Fillieule, O. (2001). Propositions pour une analyse processuelle de l'engagement individuel. Revue française de science politique, 51(1), 199-215. Doi: https://doi.org/10.3917/rfsp.511.0199

Fillieule, O. (2012). Le désengagement d'organisations radicales. Approche par les processus et les configurations. Lien Social et Politiques, (68), 37 59. https://doi.org/10.7202/1014804ar 
Fillieule, O., \& Tartakosky, D. (2015). La Manifestación. Cuando la acción colectiva toma las calles. Buenos Aires: Siglo Veintiuno Editores.

Fillieule, O., \& Accornero, G. (2016). Introduction. "So many as the stars of the sky in multitude, and as the sand which is by the sea shore innumerable": European Social Movement Research in Perspective. En O. Fillieule, G. Accornero (Ed.), Social Movement Studies in Europe. The State of the Art (pp. 1-20). New York, Oxford: Berghahn Books.

Gerbaudo, P. (2016). The indignant citizen: anti-austerity movements in southern Europe and the anti-oligarchic reclaiming of citizenship. Social Movement Studies, 16(1), 36-50. https://doi.org/10.1080/147428 37.2016.1194749

Gustavo Sylvestre Política y Actualidad (2014, 22 de mayo). Precios Cuidados: "Con la Red Comprar se busca incluir a pequeños almacenes y supermercados regionales", dijo Santiago Fraschina. Gustavo Sylvestre Política y Actualidad. Recuperado de http:/ /www.gustavosylvestre. $\mathrm{com} /$ politica/precios-cuidados-con-la-red-comprar-se-busca-incluira-pequenos-almacenes-y-supermercados-regionales-dijo-santiagofraschina/).

Huckfeldt, R. (1979). Political Participation and the Neighborhood Social Context. American Journal of Political Science, 23(3), 579-592. https: / / doi.org/10.2307/2111030.2307/2111030

Ion, J. (1997). La fin des militants? París: Les Éditions de l'Atelier.

Kenny, C. B. (1992). Political Participation and Effects from the Social Environment. American Journal of Political Science, 36(1), 259-67. https: / / doi.org/10.1080/14742837.2016.11947

Kitschelt, H. (2004). Diversificación y reconfiguración de los sistemas de partidos de las democracias postindustriales. Revista Española de Ciencia Política, (10), 9-51.

Kitts, J. (2000). Mobilizing in Black Boxes: Social Networks and Participation in Social Movement Organizations. Mobilization: An International Quartely, 5(2), 241-257. https://doi.org/10.1177/000312240807300606

Klandermans, P. G. (1984). Mobilization and participation in trade union action: An expectancy-value approach. Journal of Occupational Psychology, 57(2), 107-120. https://doi.org/10.1111/j.2044-8325.1984.tb00153.x

Klandermans, P. G., \& Oegema, D. (1987). Potentials, Networks, Motivations, and Barriers: Steps Towards Participation in Social Mo- 
vements. American Sociological Review, 52(4), 519-531. https://doi. org $/ 10.2307 / 2095297$

La Due Lake, R., \& Huckfeldt, R. (1998). Social Capital, Social Networks, and Political Participation. Political Psychology, 19(3), 567-584.

Lafont, M. V. (2001). Les jeunes militants du Front national: Trois modèles d'engagement et de cheminement. Revue Française de Science Politique, 51(1), 175-198. https://doi.org/10.3917/rfsp.511.0175

Lagos, M., \& Gutiérrez, M. (2006). Dictadura, democracia y políticas neoliberales1976 - 1999. En M. Lagos \& A. Teruel (Dirs.), Jujuy en la historia: de la colonia al siglo XX (pp. 234-294). Jujuy: Unidad de Investigación en Historia Regional, Facultad de Humanidades y Ciencias Sociales, Universidad Nacional de Jujuy.

Lagos, M., \& Gutiérrez, M. (2009). La década del menemismo y la ingobernabilidad en Jujuy. Nación, Región y Provincia en los Noventa. En M. Lagos (Coord.), Jujuy bajo el signo neoliberal. Politica, sociedad y cultura en la década del noventa (pp. 65-127). Jujuy: Unidad de Investigación en Historia Regional, Facultad de Humanidades y Ciencias Sociales, Universidad Nacional de Jujuy.

Laudano, C. (2017). Movilizaciones \#niunamenos y \#vivasnosqueremos en Argentina. Entre el activismo digital y \# elfeminismolohizo. Ponencia presentada en el Seminário Internacional Fazendo Gênero 11 \& 13th Women's Worlds Congress (Anais Eletrônicos), Florianópolis, Brasil.

Leighley, J. E. (1990). Social Interaction and Contextual Influences on Political Participation. American Politics Research, 18(4), 459-475. https:/ / doi.org/10.1177/1532673X9001800404

Mauro, S. (2011). Transformaciones en la política argentina. La conformación del peronismo no kirchnerista como coalición partidaria nacional (2005-2009). Revista de Investigación Social, 8(12), 9-38.

Mauro, S. (2014). Representación política y movilización social en la Argentina postneoliberal (2003-2013). Politica Revista de Ciencia Politica, 52(1), 171-193. https://doi.org/10.5354/0716-1077.2014.33103

McAdam, D. (1982). Political Process and Development of Black Insurgency, 19301970. Chicago: The University of Chicago Press.

McAdam, D. (1988). Freedom Summer. Oxford: Oxford University Press.

McClurg, S. D. (2003). Social Networks and Political Participation: The Role of Social Interaction in Explaining Political Participation. Political Research Quarterly, 56(4), 449-464. https://doi.org/10.1177/106591290305600407 
Meccia, E. (2012). Subjetividades en el puente. El método biográfico y el análisis microsociológico del tránsito de la homosexualidad a la gaycidad. Revista Latinoamericana de Metodología en Investigación Social, (4), 38-51.

Meccia, E. (2015). Cambio y narración. Las transformaciones de la homosexualidad en Buenos Aires según los relatos de homosexuales mayores. Sexualidad, Saludy Sociedad (Río de Janeiro), (19), 11-43. https: / / doi.org/10.1590/1984-6487.sess.2015.19.04.a

Milbrath, L. (1965). Political Participation: How and Why Do People Get Involved in Politics? Chicago: Rand McNally \& Company.

Milbrath, L. (1981). Political Participation. En S. Long (Ed.), The Handbook of Political Behavior 4 (pp. 197-240). Nueva York: Plenum Press.

Modonesi, M. (2016). Elprincipio antagonista. Marxismo y acción política. México D. F.: Universidad Nacional Autónoma de México (UNAM), Editorial Ítaca.

Moscovich, L. (2013). Gobernadores versus organizaciones: apoyos federales, política provincial y protesta. Revista SAAP, 7(1), 131-159.

Nie, N. H., Bingham Powell, G., \& Prewitt, K. (1969). Social Structure and Political Participation: Developmental Relationships, Part I. The American Political Science Review, 63(2) 361-378. https://doi.org/10.1017/ S0003055400262278

Organización Laboral Juanita Moro. Nuestro perfil. Organización Laboral Juanita Moro. Recuperado de http://juanitamoro.blogspot.com/p/ acerca-de-la-juanita-moro-ong.html

Passy, F. (2002). Social Networks Matter. ButHow? En M. Diani \& D. McAdam (Eds.), Social Movement and Networks: Relational Approach to Collective Action (pp. 21-48). NuevaYork: Oxford University Press.

Passy, F., \& Giugni, M. (2000). Life-Spheres, Networks, and Sustained Participation in Social Movements: A Phenomenological Approach to Political Commitment. Sociological Forum, 15(1), 117-144.

Pastore, M. (2010). La utopía revolucionaria de los años ‘60. Buenos Aires: Ediciones del Signo.

Pereyra, S., Vommaro, G., \& Pérez, G. (Eds.). (2013). La Grieta: Política, economía y cultura después del 2001. Buenos Aires: Editorial Biblios.

Portantiero, J. C. (1978). Juan Carlos, Estudiantes y politica en América Latina: el proceso de la reforma universitaria (1918 - 1938). México D. F: Siglo Veintiuno.

Poupeau, F. (2007). Dominación y movilizaciones. Estudios sociológicos sobre el capital militante y el capital escolar. Córdoba: Ferreyra Editor. 
Pudal, B. (2011). Los enfoques teóricos y metodológicos de la militancia. Revista de Sociología, (25), 17-35. https://doi.org/10.5354/0716632X.2011.27495

Romanos, E. (2017). Late Neoliberalism and Its Indignados: Contention in Austerity Spain. En D. Della Porta, M. Andretta, T. Fernandes, F. O'Connor, E. Romanos, \& M. Vogiatzoglou (2017). Late Neoliberalism and its Discontents in the Economic Crisis. Comparing Social Movements in the European (pp. 131-168). Cham: Palgrave Macmillan.

Rosanvallon, P. (2007). La contrademocracia: La politica en la era de la desconfianza. Buenos Aires: Manantial.

Sakbani, M. (2011). The revolutions of the Arab Spring: are democracy, development and modernity at the gates? Contemporary Arab Affairs, 4(2), 127-147. https:// doi.org/10.1080/17550912.2011.575106

Sawicki, F., \& Siméant, J. (2009). Décloisonner la sociologie de l'engagement militant. Note critique sur quelques tendances récentes des travaux français. Sociologie du travail, 51(1), 97-125. https:/ / doi.org/10.1016/j. soctra.2008.12.006

Schorr, M., \& Wainer, A. (2005). Argentina: ¿muerte y resurrección? Notas sobre la relación entre economía y política en la transición del «modelo de los noventa» al del «dólar alto». Realidad Económica, 1(211), 32-65.

Schuster F., et al. (2006). Transformaciones de la protesta social en Argentina 1989-2003. Documento de Trabajo No48. Grupo de Estudios Sobre Protesta Socialy Acción Colectiva, Instituto de Investigaciones Gino Germani, Facultad de Ciencias Sociales, Universidad de Buenos Aires. Recuperado de http://webiigg.sociales.uba.ar/Publicaciones/DT/dt48.pdf.

Sidicaro, R. (2011). El partido peronista y los gobiernos kirchneristas. Nueva Sociedad, (234), 74-94.

Simon, B. (2011). Collective Identity and Political Engagement. En A. Azzi, X. Chryssochoou, B. Klandermans \& B. Simon (Eds.), Identity and Participation in Culturally Diverse Societies: A Multidisciplinary Perspective (pp. 137-157). Oxford: Wiley-Blackwell.

Studer, B. (2015). The Transnational World of the Cominternians. Londres, Nueva York: Palgrave Macmillan.

Tarrow, S. G. (1997). Elpoder en movimiento. Los movimientos sociales, la acción colectiva y la politica. Buenos Aires: Alianza Editorial.

Tavano, C. S. (2015). De la Túpac a Soberanía Popular: trayectoria de la Organización Barrial Túpac Amaru. Ponencia presentada en la XI Jornadas 
de Sociología, Carrera se Sociología, Facultad de Ciencias Sociales, Universidad de Buenos Aires, 13 al 17 julio, Buenos Aires, Argentina. Tilly, C., \& Tarrow, S. (2015). Contentious politics. Nueva York: Oxford University Press.

Torre, J. C. (2003). Los huérfanos de la política de partidos. Sobre los alcances y la naturaleza de la crisis de representación partidaria. Desarrollo económico, 42(168), 647-665.

van Deth, J. A. (2014). A conceptual map of political participation. Acta Politica, 49(3), 349-367. https://doi.org/10.1057/ap.2014.6

Varesi, G. Á. (2014). El gobierno de Eduardo Duhalde: hegemonía y acumulación en el inicio de la Argentina posconvertibilidad, 2002-2003. Papeles de Trabajo, 8(14), 168-191.

Vázquez, M., \& Vommaro, P. (2012). La fuerza de los Jóvenes: aproximaciones a la militancia kirchnerista desde La Cámpora. En G. Pérez \& A. Natalucci (Ed.), Vamos las bandas. Organizaciones y militancia Kirchneristas (149-174). Buenos Aires: Nueva Trilce.

Verba, S., \& Nie, N. H. (1972). Participation in America: Political Democracy and Social Equality. Nueva York: Harper \& Row.

Verba, S., Schlozman, K. L., \& Brady, H. E. (1995). Voice and Equality. Civic Voluntarism in American Politics. Cambridge: Harvard University Press.

Vecchioli, V. (2012). Repertorios militantes y expertise jurídica en la defensa de la causa de los Derechos Humanos en la Argentina: el caso de la Liga Argentina por los Derechos del Hombre. Ensamble: Revista electrónica de la Casa Argentina en París. Recuperado de https:// www.academia.edu/2063611/Repertorios_militantes_y_expertise_jur\%C3\%ADdica_en_la_defensa_de_la_causa_por_los_Derechos_Humanos_en_la_Argentina_el_caso_de_la_Liga_Argentina_por_los_Derechos_del_Hombre

Vommaro, G., \& Morresi, S. (Eds). (2015). "Hagamos equipo". PRO y la construcción de la nueva derecha en Argentina. Buenos Aires: Ediciones UNGs. 